\title{
Pengaruh Pelatihan Terhadap Kinerja Pegwai Pada Dinas Prasarana Wilayah Propinsi Sulawesi Selatan
}

\author{
Mariam Makmur *1 \\ A. Kartini Sari Putri $D^{2}$ \\ Siti Nur Azisyah Satria ${ }^{3}$ \\ 1,2.3Program Studi Manajemen, Sekolah Tinggi Ilmu Ekonomi Ichsan Sidrap, Indonesia \\ *e-mail: $\underline{\text { mariammakmur@gmail.com }}^{1}$, aksputri@gmail.com $^{2}$, stnurazisyah@gmail.com $^{3}$
}

(Naskah masuk : tgl bln thn, Revisi : tgl bln thn, Publikasi : tgl bln thn)

\begin{abstract}
Abstrak
Dalam era globalisasi sekarang ini ditandai dengan suatu persiapan yang sangat ketat, maka yang menjadi persoalan adalah menyiapkan pegawai/karyawan yang berkualitas yang mampu bersaing dengan tenagatenaga profesional dari negara lain atau dengan kata lain menyiapkan sumber daya manusia yang mempunyai keterampilan secara spesifik yang handal dan berkualitas. Penelitian ini bertujuan untuk menegetahui pengaruh pelatihan terhadap kinerja pegawai pada dinas prasarana. Dalam penelitian ini laporan penelitian ini disususun dan diselesaikan dengan pedoman pada metode library research, observasi dan wawancara, metode bermaksud menerangkan obyek yang diteliti dengan mempergunakan data dari obyek yang diteliti itu sendiri. Populasi dalam penelitian ini adalah seluruh pegawai pada Dinas Prasarana propinsi Sulawesi Selatan. Jumlah sample respondenpenelitian ini ditentukan sebnayak 30 orang. Hasil penelitian menemukan bahwa responden pegawai pada dinas prasarana pelatihan mempunyai pengaruh yang kuat dan positif terhadap peningkatan kinerja pegawai.
\end{abstract}

Kata kunci: Pelatihan, Kecakapan, Kinerja dan Metode

\begin{abstract}
In the current era of globalization marked by a very strict preparation, the problem is to prepare qualified employees who are able to compete with professional workers from other countries or in other words prepare human resources who have specific skills that are reliable. and quality. This study aims to determine the effect of training on employee performance at the infrastructure office. In this study, this research report is compiled and completed with guidelines on library research, observation and interview methods, the method intends to explain the object under study using data from the object under study itself. The population in this study were all employees at the Infrastructure Service of South Sulawesi province. The number of sample respondents in this study was determined to be 30 people. The results of the study found that employee respondents at the training infrastructure service had a strong and positive influence on improving employee performance.
\end{abstract}

Keywords: Performance and Methods, Skills, Training,

\section{PENDAHULUAN}

Dalam rangka pembangunan di seluruh tanah air, maka diperlukan adanya partisipasi dari semua pihak. Oleh sebab itu untuk mempercepat laju pembangunan tersebut, maka diharapkan kepada semua pihak baik pemerintah maupun swasta, perusahaan besar ataupun kecil ikut serta.

Peningkatan kualitas sumber daya manusia sebagai alat penggerak utama disegala bidang merupakan hal yang amat penting dan faktor penentu guna mencapai tujuan yang akan dicapai.

Dalam era globalisasi sekarang ini ditandai dengan suatu persiapan yang sangat ketat, maka yang menjadi persoalan adalah menyiapkan pegawai/karyawan yang berkualitas yang mampu bersaing dengan tenaga-tenaga profesional dari negara lain atau dengan kata lain menyiapkan sumber daya manusia yang mempunyai keterampilan secara spesifik yang handal dan berkualitas. Peningkatan sumber daya manusia sebagai alat penggerak utama disegala bidang merupakan hal yang sangat penting dan ini dapat dilakukan dengan melakukan program pelatihan. Pelatihan adalah kegiatan untuk memperbaiki dan mengembangkan sikap, tingkah laku, keterampilan dan pengetahuan dari para karyawan sesuai dengan yang diinginkan oleh instansi yang bersangkutan. 
Setiap pelatihan sebagai upaya untuk mencapai peningkatan produktivitas kerja suatu perusahaan/instansi tidak terlepas dari pengaruh, baik pengaruh dari dalam dan dari luar perusahaan/instansi tersebut. Pengaruh ini menuntut setiap organisasi perusahaan/instansi agar meningkatkan pelayanan sehingga dapat memenuhi kebutuhan masyarakat yang makin meningkat. Untuk mencapai tingkat produktivitas yang tinggi, maka pihak perusahaan/instansi harus meningkatkan kemampuan, baik pengetahuan maupun keterampilan dari karyawannya agar dapat menyesuaikan diri terhadap perubahan dalam instansi, dimana hal tersebut dapat tercapai melalui pendidikan dan latihan yang insentif.

Jenis pelatihan yang saat ini diterapkan olen Dinas Prasarana Wilayah Propinsi SulawesiSelatan sub bagian umum kepada pegawainya bersifat metode praktis dan Vestibule Training misal, pelatihan perkantoran, pelatihan perpustakaan, pelatihan keadministrasian, kursus komputer bagi pegawai yang menangani keuangan. Pada dasarnya pelatihan dilakukan agar pegawai mengetahui dan lebih memahami spesifikasi pekerjaan mereka.

Adapun yang menjadi masalah pokok sehubungan latar belakang masalah adalah: "apakah pelatihan melalui Vestibule training bias meningkatkan kinerja pegawai pada Dinas Prasarana Wilayah Propinsi Sulawesi Selatan.

\section{Tujuan Penelitian}

Tujuan penelitian ini adalah untuk mengetahui pengaruh pelatihan melalui vestibule training terhadap kinerja pegawai pada Dinas Prasarana Wilayah Propinsi Sulawesi Selatan

Menurut Faustino Cardoso Gomes, dalam buku Manajemen Sumber Daya Manusia (2003: 197) pelatihan adalah setiap usaha untuk memperbaiki performansi pekerja pada suatu pekerjaan tertentu yang sedang menjadi tangggung jawabnya, atau suatu pekerjaan yang ada kaitannya dengan pekerjaannya. Agar efektif, pelatihan biasanya harus mencakup pengalaman belajar, aktivitas-aktivitas yang terencana, dan didesain sebagai jawaban atas kebutuhankebutuhan yang berhasil diidentifikasikan. Secara ideal, pelatihan harus didesain untuk mewujudkan tujuan-tujuan dari para pekerja secara perorangan.

Hasibuan dalam bukunya Sumber Daya Manusia (2001:70) mengatakan pelatihan adalah suatu proses pendidikan jangka pendek dengan menggunakan prosedur yang sistematis dan terorganisir, sehinggakaryawan operasional belajar pengetahuan teknik pengerjaan dan keahlian untuk tujuan tertentu.

Menurut Anwar Prabu Mangkunegara (2000: 67) Kinerja adalah hasil kerja secara kualitas dan kuantitas yang dicapai oleh seorang pegawai dalam melaksanakan tugasnya sesuai dengan tanggung jawab yang diberikan kepadanya.

Dalam UU No 8 Tahun 1974 BAB 1 Pasal 1 (2005:2) mengatakan bahwa Pegawai Negeri adalah setiap warga negara Republik Indonesia yang telah memenuhi syarat yang ditentukan, diangkat oleh pejabat yang berwenang dan diserahi tugas dalam suatu jabatan negeri, atau diserahi tugas negara lainnya, dan digaji berdasarkan peraturan perundang-undangan yang berlaku.

\section{Kerangka Pikir}

Agar pengumpulan data lebih terarah, maka penulis mengambil data sesuai dengan judul "Pengaruh Pelatihan Terhadap Kinerja Pegawai pada Dinas Prasarana Wilayah Propinsi Sulawesi Selatan", dan lebih mengkhususkan lagi ke sub bagian umum pada dinas prasarana wilayah propinsi sulawesi selatan.

Adapun yang menjadi kerangka pikir dalam penyusunan skripsi ini adalah untuk lebih memahami bagaimana pengaruh pelatihan terhadap peningkatan kinerja pegawai.

Berdasarkan masalah pokok dan landasan teori yang dikemukakan maka hipotesis yang diajukan dalam penelitian ini adalah diduga bahwa pelatihan melalui vestibule training berpengaruh positif terhadap kinerja pegawai pada Dinas Prasarana Wilayah Propinsi Sulawesi Selatan.

\section{Bagan Alur Kerangka Pikir}




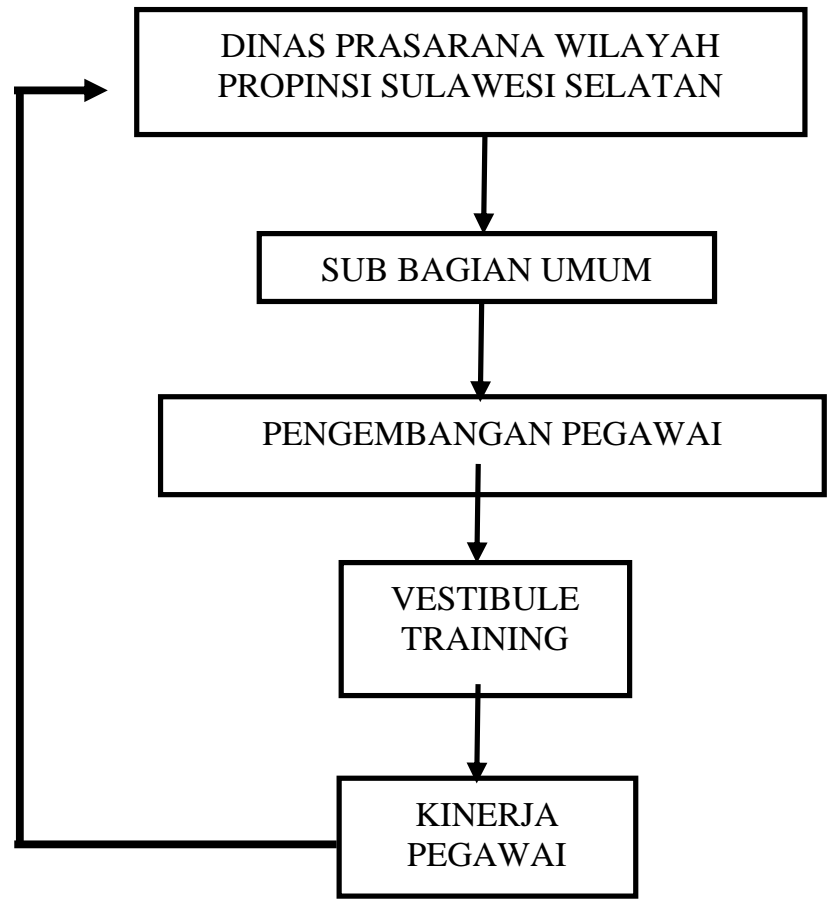

Gambar 1. Pengaruh Pelatihan Terhadap Kinerja Pegwai Pada Dinas Prasarana Wilayah Propinsi Sulawesi Selatan

\section{METODE}

Penelitian dilakukan dalam wilayah administrasi di Makassar pada Dinas Prasarana Wilayah Propinsi Sulawesi Selatan, yang beralamat di jalan A.P. Pettarani, sebagai objek penelitian sekaligus sebagai tempat pengambilan data.

Adapun waktu penelitian dan pengambilan data dilakukan sampai dengan penyusunan dilakukan selama dua bulan Metode yang dipergunakan dalam penelitian ini adalah studi kasus, dengan tahapan sebagai berikut: Penelitian pustaka (Library Research), Penelitian lapang (Field Research), Untuk mendapatkan data lapangan ini, digunakan Teknik Wawancara dan Observasi.

Jenis data adalah data kualitatif dan kuantitatif. Objek penelitian berdasarkan hasil observasi dan wawancara dengan mengedarkan kuesioner tertutup kepada para karyawan pada sub bagian umum yang merupakan populasi dari penelitian ini yang berjumlah 30 orang adalah jumlah sampel yang diambil dari populasi tersebut. Dalam penelitian ini menggunakan metode Analisis Deskriptif, yaitu metode yang digunakan untuk menjelaskan metode pelatihan yang digunakan dalam peningkatan kinerja pada Dinas Prasarana Wilayah sub Bagian Umum Propinsi Sulawesi-selatan. Dengan menggunakan metode sampling jenuh dimana semua populasi digunakan sebagai sebagai sample yang berjumlah 30 responden. Analisis Rating Scala, yaitu data mentah yang didapat berupa angka kemudian ditafsirkan dalam pengertian kualitatif. Dalam hal ini pemberian kuesioner kepada responden yang telah mempunyai nilai jawaban.

\section{Metode Analisis}

Dalam penelitian ini mempunyai tujuan untuk melihat pengaruh hubungan antara variabel independen terhadap variabel dependen dengan menggunakan analisis regresi linier berganda yang akan diolah menggunakan SPSS. Teknik analisis regresi linier berganda digunakan untuk mengetahui pengaruh variabel bebas (lingkungan kerja terhadap semangat kerja dan kegairahan kerja) secara parsial. Data yang dikumpulkan dalam penelitian ini diolah dan kemudian dianalisis dengan berbagai uji statistik sebagai berikut:

1. Analisis Statistik Deskriptif

Analisis statistik deskriptif memberikan gambaran atau deskripsi suatu data yang dilihat dari nilai rata-rata (mean), standar deviasi, varian, maksimum, minimum, sum, range, kurtosis, dan skewness (kemencengan distribusi). Hal ini perlu dilakukan untuk melihat gambaran 
keseluruhan dari sampel yang berhasil dikumpulkan dan memenuhi syarat untuk dijadikan sampel penelitian.

2. Analisis Regresi

Di dalam analisis regresi, selain mengukur kekuatan hubungan antara dua variabel atau lebih, juga menunjukkan arah hubungan antara variabel dependen dengan variabel independen. Variabel dependen diasumsikan random, yang berarti mempunyai distribusi probabilistik. Variabel independen diasumsikan memiliki nilai tetap (dalam pengambilan sampel yang berulang). Analisis yang digunakan dalam penelitian ini adalah analisis regresi berganda dengan melihat pengaruh antara status sosial orang tua, gaya hidup, dan pembelajaran diperguruan tinggi terhadap literasi keuangan. Perumusan model regresi yang digunakan adalah sebagai berikut:

$$
\mathrm{Y}=\mathrm{a}+\mathrm{b} 1 \mathrm{X} 1+\mathrm{e} 9
$$

Keterangan:

$\mathrm{Y}=$ Peningkatan Produktivitas karyawan

$\mathrm{a}=$ Konstanta

$\mathrm{b}=$ Koefisien regresi variabel independen

$\mathrm{X} 1$ = Motivasi

$\mathrm{e}=$ Error term

\section{HASIL DAN PEMBAHASAN}

Tabel 1. Jumlah Pegawai Yang Mengikuti Pelatihan Pada Dinas Prasarana Wilayah Sub Bagian Umum Propinsi Sulawesi Selatan Tahun 2017 S/D 2021

\begin{tabular}{cccc}
\hline Tahun & $\begin{array}{c}\text { Jumlah Pegawai } \\
\text { (Orang) }\end{array}$ & $\begin{array}{c}\text { Jumlah Pegawai Yang } \\
\text { Mengikuti Pelatihan (Orang) }\end{array}$ & $\begin{array}{c}\text { Perkembangan } \\
\text { (\%) }\end{array}$ \\
\hline 2017 & 28 & 4 & - \\
2018 & 28 & 7 & 75,00 \\
2019 & 28 & 9 & 28,57 \\
2020 & 28 & 12 & 33,33 \\
2021 & 30 & 17 & 41,67 \\
& Rata-rata Laju Perkembangan (\%) & 35,71 \\
\hline
\end{tabular}

Berdasarkan tabel $1 \mathrm{di}$ atas dapat dilihat terjadi peningkatan jumlah pegawai yang mengikuti pelatihan. tahun 2017 terjadi peningkatan dari 4 orang menjadi 7 orang pada tahun 2018 dan perkembangannya sebesar $75 \%$ pada tahun 2019 meningkat menjadi 9 orang dan perkembangannya sebesar $28,57 \%$, tahun 2020 juga meningkat menjadi 12 orang dan persentase perkembangannya sebesar 33,33\%, dan pada tahun 2021 meningkat menjadi 17 orang dan persentase perkembangannya sebesar $41,67 \%$.

Dapat dilihat bahwa dalam kurun waktu lima tahun (2017 s/d 2021) jumlah pegawai yang mengikuti pelatihan, rata-rata laju perkembangannya sebesar 35,71\%. Adapun persentase perbandingan antara jumlah karyawan yang mengikuti pelatihan dan yang belum mengikuti pelatihan, dapat dilihat pada tabel 2 .

Berdasarkan tabel 2, perbandingan antara jumlah karyawan yang mengikuti pelatihan dan yang belum memperoleh kesempatan untuk mengikuti pelatihan pada tahun 2017 adalah $14,29 \%$ dan yang belum mengikuti pelatihan 85,71 \%, pada tahun 2018 adalah $25,00 \%$ dan yang belum mengikuti pelatihan 75,00 \%, pada tahun 2019 yang mengikuti pelatihan $32,14 \%$ dan yang belum mengikuti pelatihan 75,00 \%, tahun 2020 yang mengikuti pelatihan sebesar $42,86 \%$ dan yang belum mengikuti pelatihan $57,14 \%$, dan pada tahun 2021 yang mengikuti pelatihan $56,67 \%$ dan yang belum mengikuti pelatihan $10,00 \%$.

Jadi perbedaan yang mengikuti pelatihan dan belum mengikuti pelatihan cukup besar. Hal ini tentu saja harus mendapat perhatian yang khusus. Rata-rata jumlah pegawai yang telah 
mengikuti pelatihan keseluruhan adalah sebesar 34,19\% dan karyawan yang belum mengikuti pelatihan sebesar $60,57 \%$.

Tabel 2. Perbandingan Antara Jumlah Karyawan Yang Telah dan Belum Mengikuti Pelatihan Tahun 2017 S/D 2021

\begin{tabular}{|c|c|c|c|c|c|}
\hline \multirow[t]{2}{*}{ Tahun } & \multirow[t]{2}{*}{$\begin{array}{l}\text { Jumlah Seluruh } \\
\text { Karyawan } \\
\text { (Orang) }\end{array}$} & \multicolumn{2}{|c|}{$\begin{array}{c}\text { Jumlah Karyawan Yang } \\
\text { Telah } \\
\text { Mengikuti Pelatihan } \\
\text { (Orang) }\end{array}$} & \multicolumn{2}{|c|}{$\begin{array}{l}\text { Jumlah Karyawan } \\
\text { Yang Belum } \\
\text { Mengikuti Pelatihan } \\
\text { (Orang) }\end{array}$} \\
\hline & & Pegawai & $\%$ & Pegawai & $\%$ \\
\hline 2017 & 28 & 4 & 14,29 & 24 & 85,71 \\
\hline 2018 & 28 & 7 & 25,00 & 21 & 75,00 \\
\hline 2019 & 28 & 9 & 32,14 & 21 & 75,00 \\
\hline 2020 & 28 & 12 & 42,86 & 16 & 57,14 \\
\hline 2021 & 30 & 17 & 56,67 & 3 & 10,00 \\
\hline & Rata-rata & & 34,19 & & 60,57 \\
\hline
\end{tabular}

Adapun bentuk pelatihan yang diterapkan oleh Dinas Prasarana Wilayah Propinsi Sulawesi Selatan Sub Bagian Umum adalah jenis pelatihan Vestibule Training, pelatihan yang dilakukan diluar lingkungan tempat kerja serta menggunakan tenaga pengajar yang berpengalaman dan juga berasal dari luar kantor.

Tabel 3. Jenis Pelatihan Pegawai Pada Dinas Prasarana Wilayah Sub Bagian Umum Propinsi Sulawesi Selatan Tahun 2021

\begin{tabular}{|c|c|c|c|}
\hline No & $\begin{array}{c}\text { Jenis Pelatihan } \\
\text { Pegawai }\end{array}$ & Sistem Latihan & Uraian \\
\hline 1 & $\begin{array}{c}\text { Jenis Pelatihan } \\
\text { Pegawai }\end{array}$ & Vestibule Training & $\begin{array}{l}\text { Dasar - dasar } \\
\text { kepegawaian }\end{array}$ \\
\hline 2 & $\begin{array}{c}\text { Kursus keterampilan } \\
\text { / pembinaan } \\
\text { pegawai }\end{array}$ & Vestibule Training & $\begin{array}{c}\text { Cara-cara } \\
\text { pengarsipan }\end{array}$ \\
\hline 3 & $\begin{array}{l}\text { Bimbingan teknis } \\
\text { kearsipan }\end{array}$ & Vestibule Training & $\begin{array}{c}\text { Peningkatan SDM } \\
\text { dalam bidang } \\
\text { hokum }\end{array}$ \\
\hline 4 & $\begin{array}{l}\text { Kursus peningkatan } \\
\text { dan pengembangan } \\
\text { SDM bidang hukum }\end{array}$ & Vestibule Training & \\
\hline 5 & $\begin{array}{l}\text { Perpustakaan } \\
\text { perkantoran }\end{array}$ & Vestibule Training & $\begin{array}{l}\text { Pelatihan } \\
\text { Sekertaris }\end{array}$ \\
\hline 6 & $\begin{array}{l}\text { Kursus keterampilan } \\
\text { kesekretariatan }\end{array}$ & Vestibule Training & \\
\hline 7 & $\begin{array}{c}\text { Diklat pimpinan } \\
\text { Tingkat IV (ADUM) }\end{array}$ & Vestibule Training & \\
\hline 8 & $\begin{array}{c}\text { Sosialisasi peraturan } \\
\text { mentri PU No. } \\
\text { 603/PRT/M?2005 }\end{array}$ & Vestibule Training & \\
\hline 9 & $\begin{array}{l}\text { Diklat teknis } \\
\text { administrasi } \\
\text { perkantoran }\end{array}$ & Vestibule Training & $\begin{array}{c}\text { Pengadaan } \\
\text { inventaris kantor }\end{array}$ \\
\hline
\end{tabular}

Berdasarkan Tabel 3 diatas yakni jenis pelatihan pegawai menunjukkan bahwa metode pelatihan yang diterapkan oleh Dinas Praswil Propinsi Sulawesi Selatan meruakan metode pelatihan Ekstern atau pelatihan yang dilakukan diluar kantor (Vestibule Training). 
Tabel 4. Rekapitulasi Jawaban 30 Responden

\begin{tabular}{|c|c|c|c|c|c|c|c|c|c|c|c|c|c|c|c|c|c|c|c|c|c|}
\hline \multirow{2}{*}{ No } & \multicolumn{20}{|c|}{ Jawaban responden untuk item nomor ke ........ } & \multirow{2}{*}{ Jumlah } \\
\hline & 1 & 2 & 3 & 4 & 5 & 6 & 7 & 8 & 9 & 10 & 11 & 12 & 13 & 14 & 15 & 16 & 17 & 18 & 19 & 20 & \\
\hline 1 & 5 & 5 & 5 & 3 & 4 & 4 & 3 & 3 & 3 & 3 & 4 & 3 & 5 & 4 & 3 & 3 & 4 & 4 & 3 & 4 & 75 \\
\hline 2 & 5 & 5 & 5 & 3 & 4 & 4 & 4 & 4 & 4 & 3 & 4 & 4 & 5 & 5 & 4 & 3 & 3 & 4 & 4 & 4 & 81 \\
\hline 3 & 5 & 5 & 4 & 3 & 5 & 4 & 5 & 4 & 4 & 3 & 3 & 4 & 5 & 3 & 4 & 5 & 4 & 5 & 3 & 4 & 82 \\
\hline 4 & 5 & 4 & 4 & 4 & 5 & 3 & 3 & 3 & 4 & 5 & 4 & 4 & 3 & 4 & 5 & 5 & 4 & 3 & 3 & 5 & 80 \\
\hline 5 & 5 & 5 & 5 & 3 & 4 & 4 & 4 & 4 & 4 & 3 & 4 & 4 & 5 & 5 & 4 & 3 & 3 & 4 & 4 & 4 & 81 \\
\hline 6 & 5 & 5 & 5 & 3 & 5 & 4 & 5 & 3 & 4 & 3 & 4 & 3 & 5 & 5 & 4 & 3 & 4 & 4 & 4 & 4 & 82 \\
\hline 7 & 5 & 4 & 3 & 4 & 5 & 4 & 4 & 4 & 4 & 3 & 4 & 3 & 4 & 5 & 3 & 4 & 3 & 3 & 4 & 3 & 76 \\
\hline 8 & 5 & 4 & 4 & 3 & 4 & 3 & 5 & 4 & 4 & 3 & 4 & 5 & 4 & 3 & 3 & 4 & 3 & 4 & 3 & 3 & 75 \\
\hline 9 & 5 & 4 & 5 & 3 & 4 & 4 & 4 & 3 & 4 & 4 & 5 & 5 & 4 & 4 & 3 & 3 & 3 & 4 & 3 & 4 & 78 \\
\hline 10 & 5 & 5 & 5 & 4 & 3 & 4 & 4 & 5 & 4 & 3 & 3 & 4 & 4 & 4 & 3 & 4 & 4 & 4 & 5 & 5 & 82 \\
\hline 11 & 5 & 4 & 5 & 4 & 3 & 4 & 4 & 5 & 4 & 2 & 4 & 5 & 5 & 4 & 4 & 3 & 4 & 5 & 3 & 3 & 80 \\
\hline 12 & 4 & 4 & 4 & 3 & 4 & 5 & 5 & 4 & 3 & 2 & 4 & 4 & 4 & 5 & 4 & 4 & 3 & 4 & 4 & 4 & 78 \\
\hline 13 & 5 & 4 & 5 & 4 & 3 & 4 & 4 & 5 & 4 & 2 & 5 & 4 & 4 & 4 & 4 & 3 & 5 & 4 & 4 & 5 & 82 \\
\hline 14 & 4 & 4 & 4 & 5 & 4 & 3 & 4 & 4 & 5 & 3 & 5 & 4 & 4 & 3 & 5 & 4 & 4 & 4 & 5 & 4 & 82 \\
\hline 15 & 5 & 5 & 5 & 4 & 3 & 4 & 4 & 3 & 5 & 4 & 5 & 4 & 3 & 4 & 5 & 4 & 3 & 4 & 4 & 4 & 82 \\
\hline 16 & 4 & 4 & 5 & 4 & 3 & 4 & 4 & 4 & 5 & 5 & 4 & 3 & 4 & 5 & 4 & 5 & 3 & 5 & 4 & 4 & 83 \\
\hline 17 & 3 & 4 & 3 & 4 & 4 & 3 & 4 & 4 & 3 & 4 & 4 & 4 & 3 & 4 & 5 & 4 & 4 & 4 & 5 & 3 & 76 \\
\hline 18 & 4 & 4 & 3 & 3 & 4 & 3 & 4 & 4 & 4 & 2 & 4 & 4 & 4 & 4 & 5 & 3 & 4 & 4 & 3 & 3 & 73 \\
\hline 19 & 3 & 4 & 4 & 3 & 4 & 4 & 5 & 4 & 4 & 3 & 3 & 4 & 4 & 5 & 4 & 4 & 3 & 3 & 4 & 4 & 76 \\
\hline 20 & 5 & 5 & 5 & 4 & 4 & 4 & 4 & 5 & 5 & 3 & 4 & 4 & 4 & 4 & 5 & 5 & 3 & 3 & 4 & 4 & 84 \\
\hline 21 & 4 & 4 & 4 & 4 & 5 & 4 & 4 & 4 & 4 & 3 & 4 & 5 & 4 & 4 & 5 & 3 & 4 & 4 & 5 & 5 & 83 \\
\hline 22 & 4 & 5 & 5 & 4 & 5 & 4 & 4 & 4 & 4 & 4 & 5 & 5 & 4 & 4 & 4 & 3 & 4 & 5 & 4 & 4 & 85 \\
\hline 23 & 5 & 5 & 5 & 4 & 5 & 4 & 4 & 4 & 4 & 4 & 5 & 4 & 4 & 5 & 5 & 4 & 4 & 4 & 5 & 5 & 89 \\
\hline 24 & 4 & 3 & 3 & 4 & 4 & 4 & 5 & 4 & 3 & 3 & 3 & 3 & 4 & 3 & 4 & 4 & 3 & 4 & 3 & 3 & 71 \\
\hline 25 & 4 & 5 & 5 & 4 & 4 & 5 & 5 & 5 & 4 & 3 & 4 & 4 & 5 & 4 & 4 & 5 & 3 & 4 & 4 & 4 & 85 \\
\hline 26 & 5 & 4 & 5 & 4 & 4 & 3 & 3 & 3 & 4 & 4 & 4 & 4 & 4 & 4 & 4 & 5 & 3 & 4 & 4 & 4 & 79 \\
\hline 27 & 5 & 5 & 5 & 3 & 3 & 4 & 4 & 4 & 4 & 5 & 4 & 5 & 4 & 4 & 5 & 3 & 3 & 4 & 3 & 3 & 80 \\
\hline 28 & 4 & 4 & 4 & 4 & 5 & 4 & 5 & 5 & 4 & 3 & 5 & 4 & 4 & 4 & 5 & 4 & 3 & 4 & 4 & 4 & 83 \\
\hline 29 & 4 & 4 & 5 & 4 & 4 & 4 & 4 & 5 & 3 & 4 & 4 & 4 & 5 & 4 & 4 & 4 & 4 & 5 & 4 & 4 & 83 \\
\hline 30 & 5 & 5 & 5 & 4 & 5 & 4 & 4 & 4 & 4 & 3 & 5 & 5 & 4 & 4 & 5 & 4 & 4 & 5 & 5 & 5 & 89 \\
\hline & & & & & & & & & & & & & im & h S & & sil & ng & $\mathrm{mp}$ & $\operatorname{lan} I$ & ata & 2415 \\
\hline
\end{tabular}

\section{Pengaruh Pelatihan terhadap Kinerja Pegawai}

Jika jumlah skor hasil pengumpulan data sebesar $=2415$ didapat dari jumlah skor hasil pengumpulan kuesioner, dengan demikian pengaruh pelatihan dalam peningkatan kinerja menurut persepsi dari 30 responden adalah sebagai berikut:

$$
\begin{aligned}
\text { Nilai } & =\frac{\text { Jumlah hasil pengumpulan }}{\text { Jumlah skor kriterium }} \times 100 \% \\
& =\frac{2415}{3000} \times 100 \% \\
& =0,805 \\
& =80 \%
\end{aligned}
$$

Apabila diinterpretasikan nilai $80 \%$ terletak pada daerah kuat, sedangkan nilai 2415 yang merupakan hasil dari pemberian kuesioner berada diantara kategori baik dan sangat baik. 
Jadi bisa disimpulkan bahwa pelatihan dengan menggunakan model Vestibule training membawa pengaruh yang sangat besar bagi peningkatan kinerja pegawai selama tahun 2017 / 2021 . Peningkatan kinerja pegawai telah mencapai peningkatan yang sangat tinggi, seetelah diadakannya pelatihan peningkatan kinerja dari kriterium yang ditetapkan. Secara Kontinum dapat dibuat kategori sebagai berikut:

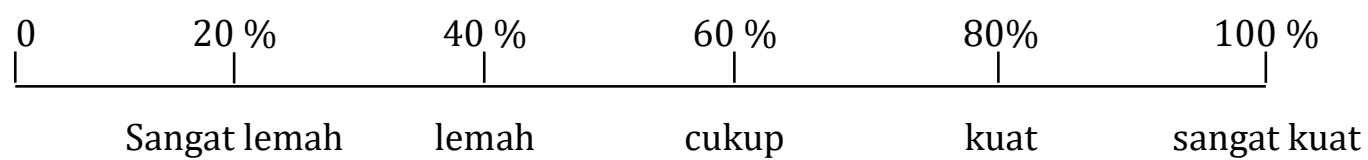

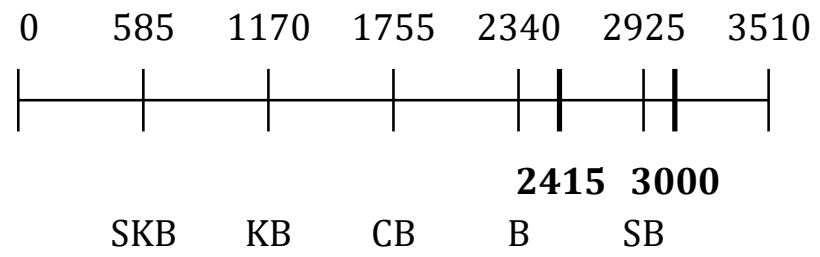

\section{KESIMPULAN}

Berdasarkan hasil analisis dan dan pembahasan yang telah diuraikan sebelumnya, maka kesimpulan dari keseluruhan hasil analisis tersebut adalah berdasarkan hasil analisis mengenai pelatihan, nampak bahwa pelakanaan pelatihan yang dilakukan oleh Dinas Prasarana Wilayah Propinsi Sulawesi Selatan telah dilakukan secara efektif dan efisien, sehingga berdampak pada kinerja pegawai yang terus mengalami peningkatan setiap tahunnya. Dari hasil perhitungan kuesioner karyawan selama tahun 2017/ 2021 menunjukkan bahwa kinerja pegawai mengalami peningkatan setiap tahunnya. Berdasarka hasil analisis pengaruh pelatihan terhadap kinerja pegawai, menunjukkan bahwa antara jumlah pegawai yang mengikuti pelatihan mempunyai pengaruh yang kuat dan positif dalam peningkatan kinerja pegawai.

Sebagai masukan atau perbandingan bagi pihak instansi agar perlunya dilakukan peningkatan pelaksanaan pendidikan dan pelatihan agar kinerja karyawan dapat meningkat. Perlunya pelaksanaan pelatihan yang lebih efisien dan efektif, hal ini dimaksudkan untuk dapat lebih meningkatkan kinerja karyawan.

\section{DAFTAR PUSTAKA}

Budiartha, I. G. N., Bagia, I. W., Suwendra, I. W. (2015). Pengaruh pelatihan dan motivasi kerja terhadap produktivitas kerja karyawan. E-Jurnal Bisma Universitas Pendidikan Ganesha 3(1):1-10.

Ernanto, B., Baga, L. M., \& Sunarti, E. (2015). Pengaruh penerapan budaya perusahaan terhadap motivasi kerja dan kinerja karyawan di PT. Rekayasa Industri. Jurnal Aplikasi Bisnis dan Manajemen 1(1):1-11

Gomes, F. C. (2003). Manajemen Sumber Daya Manusia. Cetakan ke 4. Andi Offset, Yogyakarta.

Hasibuan, H. M. (2000). Manajemen Sumber Daya Manusia. Edisi revisi, cetakan ke 3. Penerbit PT. Bumi Aksara. Jakarta.

Nazar, F., Astuti, E. S., \& Riza, M. F. (2014). Pengaruh pendidikan dan pelatihan terhadap motivasi kinerja karyawan PT BTPN Malang. Jurnal Admnistrasi Bisnis 13(1):1-9.

Nur, R. A. P. M. (2016). Pengaruh Pelatihan Kerja Dan Motivasi Kerja Terhadap Kinerja Karyawan Pada Pt Trias Sentosa, Krian Sidoarjo Fransisca Rachmawati", Akuntansi, Ekonomi dan Manajemen Bisnis, 4(1), pp. 41-46.

Muizu, Wa, O. Z. (2014). Pengaruh Kepemimpinan Terhadap Kinerja Karyawan. Pekbis Jurnal, 6(1), h: $1-13$

Pakpahan, E. S., Siswidiyantoo, S. (2014). Pengaruh pendidikan dan pelatihan terhadap kinerja 
karyawan. Jurnal Administrasi Publik 2(1):116-121.

Prabu, M. A. (2002). Manajemen Sumber Daya Manusia Perusahaan. PT. Remaja Rosdakarya. Bandung.

Undang-Undang No. 8 tahun 1974 BAB 1 Pasal 1 tentang Undang-Undang Kepegawaian Lengkap. 2005. Sinar Grafika. Jakarta.

Sahanggamu, P. M. M. S. L. (2014). Pengaruh pelatihan kerja, motivasi dan disiplin kerja terhadap kinerja karyawan pada PT. Bank Perkreditan Rakyat Dana Raya. Jurnal EMBA 2(4):514-523.

Trisofia, J. M., et.al, (2015). Pengaruh Pelatihan, Pengalaman dan Lingkungan Kerja Terhadap Kinerja Karyawan Pada PT. Bangun Wenang Beverages Company Manado. Jurnal Emba. 3(1): 737-747

Yuyun, Y. D. et.al. (2017). Pengaruh Pelatihan terhadap Motivasi Kerja dan Kinerja di Prama Sanur Beach Bali. E-Jurnal Ekonomi dan Bisnis Universitas Udayana. 1265-1290.

Yusuf, M. (2015). Pengaruh diklat dan displin kerja terhadap produktivitas kerja pegawai pada dinas kehutanan dan perkbunan Kabupaten Bireuen. Jurnal Kebangsaan 4(7): 27-34. 